\title{
EDUCAÇÃO INTEGRAL: PROPOSTA PARA UMA EDUCAÇÃO POPULAR
}

\author{
Juliana Godói Alvarenga ${ }^{\mathrm{i}}$ \\ Clarissa Moura Quintanilha ${ }^{\text {ii }}$
}

\begin{abstract}
Resumo: O presente artigo tem como foco a compreensão ideológica e filosófica dos caminhos iniciais na perspectiva da formação da classe trabalhadora. Baseado no pressuposto teóricometodológico de Paulo Freire (2005) e Darcy Ribeiro (1986) enveredados pela consolidação de uma política educacional que busca compreender o caminho percorrido para os atuais posicionamentos sobre a educação popular. A relação entre a Educação Integral e formação da classe popular sempre esteviram intimamente ligadas. Ao refletirmos a ideologia da Educação Brasileira como consolidada através dos Centros Integrados de Educação Pública (CIEPs) por Darcy Ribeiro, observamos que a educação em tempo integral está problematizada em sua gênese na educação popular. Todo seu processo tem a ferramenta para um posicionamento dialógico, inclinados para que possamos entender o panorama atual da educação pública, gratuita e para a classe popular.
\end{abstract}

Palavraschave: Educação Popular. Educação Integral. Educação Pública.

\section{INTEGRAL EDUCATION: PROPOSAL FOR POPULAR EDUCATION}

\begin{abstract}
The present discussion focuses on the ideological and philosophical comprehension of the initial paths in the perspective of the working class formation. Based on the theoreticalmethodological presupposition of Paulo Freire (2005) and Darcy Ribeiro (1986) engaged by the consolidation of an educational policy that seeks to understand the path taken for the current popular education position. The relationship between Full-Time Education and Popular Class Formation had always been closely linked. When reflecting the ideology of Brazilian Education as consolidated through the Integrated Centers of Public Education (CIEPs) by Darcy Ribeiro, we observe that full-time education is problematized in its genesis in popular education. All of its process has the tool for a dialogical positioning, inclined so that we can understand the current panorama of public education, free and for the popular class.
\end{abstract}

Keywords: Popular Education. Integral Education. Public Education.

\section{Introdução}

Com base na reflexão acerca da educação pensada para as classes populares, através do modelo da escola em tempo integral, e a discussão presente na dissertação Narrativas- 
Formadoras na Escola de Tempo Integral de Itaboraí: formação docente no período extraclasse, defendida no ano de 2017, na Faculdade de Formação de Professores da Universidade do Estado do Rio de Janeiro, objetivamos delinear os pontos de convergência da educação dos oprimidos e a formação em tempo integral. Diferentemente do que é defendido pela educação bancária, a educação libertadora de Paulo Freire, nos instiga a investigar os caminhos percorridos para a construção do cidadão.

No decorrer da investigação outras questões foram sendo elencadas, no que dizia respeito à filosofia de educação para as classes populares e de como deveria ser entendida e educação integral. No entendimento da finitude da pesquisa, obseva-se, a necessidade de retormar as bases ideológicas e filosóficas tanto do que se refere à educação para as classes populares, quanto da educação integral, entendendo a gênese da criação da educação em tempo integral para os filhos da classe trabalhadora. Seu percurso acerca da consolidação das experiências, atuamente nos soa como uma proposta assistencialista, e de controle do tempo. Contudo o que a literatura e a concepção Freireana de educação tem a nos propor é, que o percurso da construção da filosofia adotada para a educação popular nos convida refletir sobre nossa implicação no mundo. Desse modo, a lacunas deixadas no exercício dissertativo, se estabelecem nesse exercício reflexivo na busca pela consolidação de espaçostempos outros na educação.

Fundamentados sobre a metodologia da revisão de literatura, inciamos apresentando o contexto histórico e ideológico da educação para todos. Observamos o sentido e a experiência da educação em tempo integral com um caracter assistencialista e direcionado a uma determinada classe social. Em seguida, perspectivando localizar históricamente como foi consolidada a educação popular, articulamos a educação em tempo integral direcionada para os filhos da classe trabalhadora. Ao cruzarmos as duas perspectivas de análise podemos sintetizar como que ao longo do tempo a visão holítica do sujeito foi ancorrada no tange o entendimento da educação para a classe trabalhadora.

\section{Panorama histórico da Educação Popular}

As questões que iniciaram a discussão sobre a educação popular podem ser observadas a partir do manifesto da educação nova de 1932, com os pioneiros da educação. No documento, os signatários realizam o exercício de desenvolver as matrizes da educação brasileira. Com o caráter de reconstrução social e principalmente da nação. O texto faz um chamado para as questões que interferem no processo educativo, e caracteriza os pontos desarticulação e desorganização, tanto nos seus aspectos filosóficos e sociais, quanto nos métodos científicos Revista Interinstitucional Artes de Educar. Rio de Janeiro, V. 4 N. 2 - pag 378-391 (mai - ago 2018): "Dossiê 50 anos da Pedagogia do Oprimido: movimentos de opressões e emancipações contemporâneas na América Latina e África" 
utilizados no processo educativo. Para tal discussão, observa-se a passagem do entendimento de que a organização educacional deve ser entendida pela sociedade como um todo, e convoca a nação a contribuir para os ideais de construção da cultura e da valorização do conhecimento.

Como um estudioso, Fernando de Azevedo, articula a educação e a cultura de um povo, problematizando no sentido de que a educação estuda a cultura de uma civilização, ou seja,

A educação, definida como o lugar da transmissão das tradições ou das consciências coletivas, o lugar da ação coercitiva que molda os indivíduos à imagem da sociedade, é locus em que pode ser apanhado o que caracteriza o coletivo na diversidade das civilizações brasileiras, portanto, é o lugar mais fértil para o estudo da cultura brasileira. A educação contém a essência da cultura porque é o que dela é perpetuado para que se garanta a existência da consciência coletiva - dos sentimentos comuns à média dos membros de uma mesma sociedade - formando um sistema determinado que tem vida própria.[...] A educação, engendra o acesso seguro ao próprio estudo da cultura, fornecendo ao pesquisador um guia seguro para a produção da síntese da cultura e, portanto, da civilização. (AZEVEDO, 1996, p. 35).

Esse fator nos alerta para a necessidade de tomar a educação como algo público, de resistência, já que dela vai se desdobrar os rumos da organização social. Nesse sentido, a educação não pode ficar centralizada em um movimento arbitrário de modo a reproduzir o mercado, a essência da lógica pela qual ela deve ser operada funciona no sentido de relacionar o direito dos indivíduos fundamentalmente à vida e a seu desenvolvimento pleno.

No amplo campo da educação, e principalmente sobre a epistemologia da formação popular, devemos discutir e pensar as produções sociais, práticas educacionais e políticas. A conjuntura desse trabalho pautasse na articulação entre o que em uma primeira visão concebia como educação tradicional, e com o qual se objetivava o rompimento através da educação nova. E o que hoje nos desafia pensarmos acerca do movimento transformador, como nos propõe Paulo Freire como potencializador de novas leituras de mundo. Paulo Freire em sua obra Pedagogia do Oprimido (2005) insere o conceito dentro das discussões que vieram no bojo do movimento pragmático, escola novista. Tal exercício propõe o movimento de reconstrução da identidade individual, das experiências e memórias para que a partir dessa análise, possamos perceber como a formação dos sujeitos escolares oriundos das classes populares se reconhece como sujeitos da história.

Atravessados pela dialética Freireana, uma proposta Educação Popular em tempo integral, nos dá o aporte teórico-metodológico necessário, no sentido de indicar pistas do que podemos chamar de possibilidades cotidianas de construção para o método da conscientização.

Se Paulo Freire nos provoca pensar os sujeitos sociais na construção sistemática de opressores e oprimidos, não os caracterizando como bons ou maus, mas sujeitos da ação do 
mundo capitalista e mecânico do trabalho. A prática Libertadora refere-se ao que se tem como verdade, não reconhecendo a critícidade encontrada no movimento de reflexão na tessitura da prática, pois a educação não pode ser confundida com a manutenção do status quo, e sim com uma prática para a liberdade.

A educação integral deve objetivar que ninguém se liberta sozinho, nós nos libertamos coletivamente, em suas palavras,

ao defendermos um permanente esforço de reflexão dos oprimidos sobre suas condições concretas. Não estamos pretendendo um jogo divertido em nível puramente intelectual. Estamos convencidos, pelo contrário, de que a reflexão, se realmente reflexão, conduz à prática. Por outro lado, se o momento já não é o da ação, esta se fará autentica práxis se o saber dela resultante se faz objeto da reflexão crítica. (FREIRE, 2005, p.32).

O oprimido como aquele que produz a realidade não pode estar estagnando na relação oprimido-opressor, ele deve estar direcionado por uma pedagogia libertadora, entendendo que "a superação da contradição é o parto que traz ao mundo este homem novo não mais opressor; não mais oprimido, mas homem libertando-se" (Ibidem, p.38).

Em sua Práxis, seu caráter problematizador das políticas cotidianas, frutos da lógica de existência. Esse momento de reflexão nos leva a contextualizar em quais momentos somos opressões e em quais somos oprimidos? Entretanto, não querendo enquadrar nossas produções como protagonistas e antagonistas da vida social, o que vale ressaltar e imersão nas lógicas de construção do mundo, onde se deriva a maneira de estar nele, já que ao reconhecer o espaçotempo (ALVES, 2010) como capacidade de libertar os outros e a si.

Essa concepção de conhecer o outro e a si, que possibilitou que Freire desenvolvesse a teoria crítica sobre a escola bancária, considerando-a como sendo:

Nela, o educador aparece como sei indiscutível agente, como o seu real sujeito, cuja a tarefa indeclinável é "encher" os educandos dos conteúdos de sua narração. Conteúdos que são retalhos de realidade desconectados da totalidade em que se engendram e em cuja visão ganharia significação. (idem, pp. 65 - 66).

O que podemos observar com essa crítica é o colocar o educando como centro da discussão problematizadora da escola. Ou seja, a crítica vem no sentido de que na educação bancária o educando não passa de um receptáculo, produzindo a "cultura do silencio" e mantendo o objetivo opressor da classe dominante. Separar o sujeito do objeto instaura um paradigma de redução e separação, tornando-o insuficiente para compreender a complexidade do conhecimento. O pensamento dialógico deve contemplar uma comunicação em circuito, como um primeiro movimento que integre, problematize com diálogo dos saberes (MORIN, 2005). 
Para ampliarmos a discussão recorremos a Edgar Morin (2010) no qual contempla uma reforma do pensamento que irá problematizar a causalidade linear, a lógica clássica, a visão disciplinar e excludente do conhecimento e sugere sete princípios para um pensamento que une, integra, dialoga e reconhece as incertezas do saber.

O primeiro princípio é o sistêmico ou organizacional, no qual há uma ligação do conhecimento das partes com o todo. É impossível conhecer as partes sem conhecer o todo e vice-versa; esse pressuposto problematiza a visão reducionista de que o todo é maior do que as partes. "O todo é, igualmente, menos que a soma das partes, cujas qualidades são inibidas pela organização do conjunto". (MORIN, 2010, p. 94).

O segundo princípio é o hologrâmico, o qual problematiza que não somente as partes estão no todo, mas as partes contêm o todo. No campo sociológico e/ou antropológico, deparamo-nos com a noção de que o indivíduo contém a sociedade e o indivíduo pertence à sociedade. Notamos nesse ponto a importância do trabalho com as histórias de vida, em que as narrativas individuais expressam o coletivo e o social expressa a subjetividade.

O princípio seguinte, teorizado por Nobert Wiener, é do circuito retroativo, que rompe com a causalidade linear, ou seja, "a causa age sobre o efeito e o efeito age sobre a causa, como no sistema de aquecimento, em que o termostato regula o andamento do aquecedor" (ibidem, p. 94). Em outras palavras, essa interação é baseada em múltiplas retroações; no sistema político, econômico, social e psicológico nota-se a gama de possibilidades decorrentes dessas relações. O indivíduo permeado por uma cultura, uma sociedade, um ambiente familiar é um ser complexo atravessado por interações múltiplas e, ao medi-lo e/ou quantificá-lo, não percebemos os fios soltos nesse processo.

O quinto princípio é o da auto-organização, que discute o modelo auto-organizador dos seres humanos, que se autoproduzem incessantemente e por isso dependem de energia para a sua existência. Essa relação entre meio ambiente e espécie gera uma codependência entre ambos e, por esse motivo, os seres vivos são autoeco-organizadores. A vida é permeada pela morte, e para o surgimento de algo novo é necessária a morte de algo velho, mas o cerne estará contido no novo e no velho em um devir constante. Para o surgimento de novas ideias, alguns padrões precisam se transformar; para uma nova célula nascer, outras morrem e assim é tecida a teia mágica da vida.

O princípio seguinte é o dialógico, que une dois princípios ou noções que são antagônicos por essência, mas a presença de um não é a ausência do outro, ambos se constituem dialogicamente em um devir constante. 
Deve-se conceber uma dialógica ordem/desordem da organização, desde o nascimento do universo; a partir de uma agitação calorífica (desordem), em que, em certas condições (encontros aleatórios), princípios de ordem vão permitir a constituição de núcleos, átomos, galáxias e estrelas. Sob as mais diversas formas, a dialógica entre a ordem, a desordem e a organização via inúmeras inter-retroações está constantemente em ação nos mundos físico, biológico e humano (ibidem, p. 96).

A condição dialógica permite uma ampliação da noção da separatividade entre indivíduo, sociedade e cosmos, por exemplo. Um pensamento dialógico assume racionalmente a inseparatividade do homem, da sociedade e da natureza de maneira complexa.

O último princípio teorizado por Morin é o da reintrodução do conhecimento em todo conhecimento. Nesta proposta há a defesa da ideia de que todo conhecimento é uma reconstrução e/ou tradução de algo de um tempo histórico e cultural específico. O conhecimento é tecido de forma complexa, em que várias culturas, sociedades, mitos, religiões contribuíram para uma ideia.

Propor um modelo diferente da educação bancária, tão discutida por Paulo Freire é um desafio para a sociedade atual, na qual há o predomínio da fragmentação dos saberes, da hiperespecialização do conhecimento, do egocentrismo e do não cuidado com a nossa Terra mãe. É necessária uma ruptura ontológica, epistemológica e metodológica para a construção de uma verdadeira educação popular, integrando, reinventando e respeitando as diferenças ecológicas, individuais, sociais em prol de construir uma outra história.

\section{Uma iedologia de Educação Integral}

Seguindo a lógica de uma educação popular, a concepção de educação integral, em nosso momento histórico, é diferente daquela defendida e difundida por Anísio Teixeira e Darcy Ribeiro. O sentido atribuído atualmente está ligado ao tempo integral. Ou seja, a permanência do discente das classes populares pelo maior tempo possível na escola, e não a de desenvolvimento integral do sujeito, para que ele possa se desenvolver em todas as suas capacidades. Esse ideal é preconizado na experiência de Anísio Teixeira nas escolas Parques no nordeste brasileiro, e o sentido pelo qual foi ampliada no projeto de Darcy Ribeiro. Apesar de a ideia motriz estar ligada a uma mesma concepção filosófica, os seus desdobramentos são diferenciados. A centralidade era orquestrar pela laicidade, gratuidade, obrigatoriedade, e a coeducação fosse um dever permanente do Estado, baseado no sujeito escolar como um sujeito de direito.

A proposta de educação integral nos remete a um processo já bem conhecido em outros países como França e Estados Unidos, que propõem uma jornada ampliada para educação. O 
contexto de nossa educação de tempo integral está baseado nas experiências de Anísio Teixeira na década de 1950 e posteriormente, com Darcy Ribeiro na década de 80 no estado do Rio de Janeiro. Entretanto, devemos analisar que ambos os momentos contavam com um processo de escolarização muito tardio, visto que, a educação para todos, como um direito previsto na Constituição, só foi legitimado partir do movimento dos pioneiros da educação, e amadurecido pelas práticas de educadores como Paulo Freire, Florestan Fernandes, e os próprios Anísio Teixeira e Darcy Ribeiro.

A construção dos Centros Integrados de Educação Pública (CIEPs) pode ser tomada como a primeira escola popular, para atender os filhos da classe trabalhadora. Além das bases educacionais do currículo do Ciclo Básico, Darcy Ribeiro objetivava um atendimento integral do estudante com 8horas diárias na instituição, essa ampliação fazia com que o Estado tomasse para si não só a responsabilidade pela educação dos estudantes, mas também da sua alimentação, sua vida pessoal e os aspectos da cidadania de uma educação libertária. As Escolas atendiam todos os aspectos da vida do sujeito a educação, saúde, cultura, atendimento odontológico e assistência familiar. Darcy Ribeiro definia o programa dos CIEPs como a incursão do poder público na assistência pública

\begin{abstract}
A criança popular urbana, que vive em condições precárias nas favelas ou nos bairros pobres da periferia, como em tantas outras regiões do Brasil, é essencialmente diferente da criança afortunada que vive nas áreas ricas. O pequeno favelado, comendo pouco e mal, cresce raquítico. Às vezes é até prejudicado por malformações, se a fome ocorre muito cedo ou se é demasiada. (...) A criança afortunada se desenvolve bem fisicamente, fala a língua da escola, é ágil no uso do lápis e interpretação de símbolos gráficos e chega à escola altamente estimulada pelos pais através de toda espécie de prêmios e gratificações para aprender rapidamente. (RIBEIRO, 1986, p. 13).
\end{abstract}

Para além, nossas primeiras experiências com Educação Integral se deram com a implantação do Programa Especial de Educação (PEE) por meio dos CIEPs, implantados nos dois mandatos do Governo de Leonel Brizola (1983- 1987 e 1991 - 1994). O que fez com que o projeto carregasse muito mais que uma proposta de política pública de ação, mas com o costumeiro de uma experiência político-partidária. Os "brizolões", como foram vulgarmente nomeados, por estarem ligados a uma política governamental, geravam possibilidades para atender a população e combater o processo de exclusão social. Dessa forma, contemplar o projeto de educação integral no século XXI, retoma toda a discussão realizada por Anísio Teixeira e Darcy Ribeiro, com a finalidade de viabilizar que crianças e adolescentes tenham atendimento educacional de qualidade garantindo uma vida digna, baseada na construção do saber escolar. 
A educação de tempo integral nos modelos apresentados recebeu várias críticas. A política de atuação foi tomada em muitos aspectos como uma política governamental e dessa maneira, com a saída de Brizola do mandato, a proposta não foi adiante. Apenas no segundo mandato de Brizola como governador do Estado do Rio de Janeiro e com a eleição de Darcy Ribeiro para o cargo de senador, que se pôde retomar o projeto. Após as novas eleições em 1994, uma nova conjuntura política se instaurou destituindo as metas educacionais até então vigentes. Como o novo governo para o Estado do Rio Janeiro, observamos uma reestruturação do modelo educacional, retirando de cena a proposta de tempo integral. Posteriormente críticas quanto à eficácia do projeto, sua relação custo-benefício e desmonte de toda uma tradição educacional, levou ao fim do projeto dos CIEPs.

\section{Os entremeios da Educação Popular e a Educação Integral}

Analisado em uma abordagem ainda maior, podemos ousar dizer, que ao criarmos uma proposta que fala da educação integral tem na formulação das questões traçadas na metodologia com a experiência do CIEPs, tem a viabilidade de contemplavam um projeto de educação na integralidade do sujeito para o século XXI.

$\mathrm{Na}$ perspectiva deviabilizar que crianças e adolescentes tenham atendimento educacional de qualidade garantindo uma vida digna, baseada na construção do saber escolar. O processo inacabado do pretenso ensaio mostra as várias maneiras de olhar e ler o mundo, na esperança de que sua tessitura possa ser o inicio de um novo dialogo num futuro não tão distante, acreditando que as artes nos formam não como pulsões, mas como uma rede onde os fios são as postes para problemas futuros que mostraram novamente infinitas possibilidades de ser ator da vida. Já em 1986, Darcy Ribeiro, nos apresenta o quadro educacional elitista e falsas expectativas, nos diz o autor,

Suas causas, a nosso juízo, residem nas camadas mais profundas do nosso ser nacional e dizem respeito ao caráter mesmo da nossa sociedade. Tememos, até, que nós brasileiros, pela sociedade que somos e pela forma como ela está organizada, estejamos estruturados de maneira pervertida. Somos uma sociedade deformada que carrega dentro de si cicatrizes e malformações históricas profundas que temos muitas dificuldades em superar. Dificuldade tanto maiores quanto mais tardemos em reconhecê-las e em denunciá-las. (RIBEIRO, 1986, p.14).

Esses caminhos levam ao pressuposto que a finalidade da educação, tomada como uma concepção de vida, no entendimento das estruturas sociais e de classe delimitam a amplitude do poder. A educação nova deve ser tomada como uma tendência filosófica e pedagógica de seu tempo contra a velha estrutura do serviço educacional até então oferecido pela república. Ao 
contrário da educação tradicional, ou educação bancária (FREIRE, 2005), a filosofia inspiradora da educação nova, parafraseando Fernando Azevedo (2006), construi-se instintivamente pragmática, no sentido de não ser mais do que um poscionamento de classe, mas sobre tudo, uma vinculação entre a escola e a formação do ser humano.

O compromisso com a práxis tenciona a postura do educador comprometido com o oprimido, com as classes populares, pela critica as ações mecânicas. Nessa conjuntura pode ser pensado também a partir do conceito de dialogicidade, do dialogo entre os indivíduos, acreditando que "não há palavra verdadeira que não seja práxis" (idem, 2005, p. 89). Todo o processo educacional e de troca, é um processo crítico que questiona seu próprio lugar de estar, não como mera representação, mas como intervenção através palavra-ação. Ainda dialogando com Darcy Ribeiro (1986) “o fracasso brasileiro na educação - nossa incapacidade de criar uma boa escola pública a todos, com um mínimo de edicácia - é paralelo à nossa incapacidade de organizar a economia pata que todos trabalhem e comam." (idem, pp. 15 -16).

Sua abordagem não toma as dicotomias como sendo os centros dos projetos; (professoraluno; opressor-oprimido) como centro das atenções, mas seus desdobramentos mostram como essa interlocução entre a relação com as coisas mediatizados pelo mundo, e contornam a formação dos educandos das classes populares no intuito de construção. Quando analisamos que são os Oprimidos e sua intervenção social, vamos ao encontro dos movimentos consolidados desde o momento em que se começou a pensar sobre as motivações de uma educação voltada para a população. Segundo uma perspectiva dialógica do conhecimento, a relação entre a consrução histórica dos sujeitos e suas memórias de vida e formação, são o ponto de partida para uma práxis libertadora. Nesse sentido, o trabalho pedagógico sobre o prisma Freireano, tem em sua essencia a constituição de um sujeito de memórias, de experiências, de leituras e possibilidades de construção do mundo. O educador atento ao perceber nessa ponte entre a práxis e o diálogo das classes populares, como produtora de saber, ressignifica o conhecimento produzido em seu cotidiano escolar, e se reconhece como problematizador da visão holística do oprimido.

Analisamos a continuidade da vida dentro da escola, aberta a debates e construções coletivas, emancipando-se da obrigação da formação cristalizada, partindo para sua ressignificação como produto de um meio de interações.

Seu trabalho deve ser tomado como sendo essencial, pois a ação-reflexão é aquilo que fazemos na vida cotidiana. Falamos, nos movemos, expressamos pensamentos, emoções idéias, nos apaixonamos, temos ódio. Tudo o que o oprimido faz em sua vida deve ser o ponto de partida para a compreensão do mundo como ele vem sendo. É a experimentação das Revista Interinstitucional Artes de Educar. Rio de Janeiro, V. 4 N. 2 - pag 378-391 (mai - ago 2018): “Dossiê 50 anos da Pedagogia do Oprimido: movimentos de opressões e emancipações contemporâneas na América Latina e África" DOI:10.12957/riae.2018.38033 
possibilidades que a vida nos oferece, é a proposta do movimento social instaurado na criticidade das relações mais tênues, notasse por outro lado, a inversão da personagem. Não existe o ideário de uma construção representativa, o trabalho vai à contramão da lógica positivista. A sociedade não é um objeto a ser estudado ela é a sobreposição do objeto, não se trabalho no campo da iminência, é a força da ação que a constrói como objeto de discussão pelos campos onde habita. É a descritalização da opressão na relação com outro.

(...) Os sonhos são projetos pelos quais se luta. Implica, pelo contrário, avanços, recuos, marchas às vezes demoradas. Implica luta. Na verdade, a transformação do que mundo a que o sonho aspira é um ato político e seria uma ingenuidade não reconhecer que os sonhos têm seus contra-sonhos. É que o momento de que uma geração faz parte, porque histórico, revela marcas antigas que envolvem compreensões da realidade, interesses do grupo, de classes, preconceitos, geração de ideologias que se vêm perpetuando em contradições com aspectos mais modernos. Não há hoje, por isso mesmo, que não tenham "presenças" que, de há muito, perduram no clima cultural que caracteriza a atualidade concreta. Daí a natureza contraditória e processual de toda realidade. (FREIRE, 2000, p. 54).

A abordagem integral, para nós, é a relação que indica uma nova epistemologia. Uma teoria do conhecimento em que o sujeito tenha no ato de narrar a potência de ressignificar o passado à luz das experiências. Buscamos luz nas das experiências-formadoras (JOSSO, 2010) sobre implantação dessa nova perspectiva de atuação docente. A materialização da experiência como páginas em branco poderia ser vinculada à abertura para a experiência, à memória construída cotidianamente. A noção sobre a experiência assume um papel importante no campo educacional e na formação e, principalmente, nas profissões em que há interação humana com os outros, em tarefas laborativas que contenham o cuidado, a orientação e a assistência. DeloryMomberger (2016) enfatiza quatro aspectos em que há a valorização da experiência. A experiência permite identificar outras formas de aquisição do conhecimento e competências que foram adquiridas em ambientes acadêmicos. A relação entre formador e formado assume um relacionamento de pessoa para pessoa, do mundo da experiência para o universo da experiência, atuando de maneira dialógica. A experiência é concebida por meio do processo de aprendizagem ao longo do desenvolvimento humano, no qual a pessoa cria dispositivos para usá-la em outras situações cotidianas. Por último, a experiência constitui um movimento de construção de subjetividades, favorecendo uma edificação de si mesmo com a sua existência, ampliando a imagem simbólica de si. A experiência é imersa em uma pluralidade semântica que pode significar uma atividade, uma vivência, uma compreensão da pessoa pela vivência e o processo que emerge dessa vivência. (DELORY-MOMBERGER, 2016). 
A experiência pode assumir um papel ficcional: "a experiência contada certamente não é a experiência vivida, é uma representação construída, uma configuração da primeira experiência" (DELORY-MOMBERGER, 2016, p. 35). Entra em questão aqui a maneira como o sujeito se apropria da própria vida pela vida, quais significações, representações, configurações ele extrai da experiência. Em outras palavras, um momento predominantemente doloroso pode favorecer uma experiência transformadora ou um aprisionamento no sofrimento emergido, gerando assim uma tentativa de paralisação.

\section{Apontamentos finais}

Segundo as orientações da Legislação, seu direcionamento tem por excelência proporcionar um cenário favorável para a implantação dos novos rumos da educação brasileira. Não obtendo um caráter assistencialista, mas de fato, relacionando a educação com a melhoria na qualidade de vida da população. Pautados na Lei de Diretrizes e Bases da Educação (LDB), lei n ${ }^{\circ}$ 9394/96, dão um salto paradigmático ao estabelecer no cerne da discussão da expansão da escolarização nacional, a viabilidade de políticas públicas que tenham o educando como o centro da discussão educacional, alcançando a formação dos profissionais da educação, e para além sua valorização.

\footnotetext{
(...) o diálogo não é só um encontro de dois sujeitos que buscam o significado das coisas - o saber - mas um encontro que se realiza na práxis - ação + reflexão -, no engajamento, no compromisso com a transformação social. Dialogar não é trocar idéias. O diálogo que não leva ação transformadora é puro verbalismo. Em Paulo Freire o diálogo tem clara conotação política. (GADOTTI, 2010, p.15).
}

A antropologia do Paulo Freire parte da premissa de que nós somos seres curiosos, inacabados, inconclusos e portanto precisamos do outro. Ontologicamente na perspectiva freireana precisamos do outro e é com o outro que aprendemos e ensinamos. "Ensinar inexiste sem aprender e vice-versa e foi aprendendo socialmente que, historicamente, mulheres e homens descobriram que era possível ensinar." (FREIRE, 1996, p.13). Freire, aponta para uma prática pautada no diálogo, respeito, criticidade visando uma ação transformadora da realidade neoliberal. Ele também valoriza os saberes "cotidianos" dos povos ordinários, sendo assim, o saber primeiro. O aluno não separa as significações educativas das cotidianas e é a partir da leitura de mundo que adquirimos ferramentas para ler a palavra.

Paulo Freire, na prática, sabia trabalhar com várias disciplinas ao mesmo tempo: a etnografia, a teoria literária, a filosofia, a política, a economia, a sociologia, etc. Trabalhava mais com teorias do que com disciplinas ou currículos que dizia que deveriam ser ultrapassados. Insistia para que os alunos buscassem fora de seu currículo 
outros conhecimentos, na educação principalmente. Para o ato pedagógico concorrem muitas ciências. Além disso, ele trabalhava ao mesmo tempo também com várias perspectivas teóricas: a do militante político, do filósofo da libertação, do cientista, do intelectual, do revolucionário, etc. (GADOTTI, 1997, p.13).

Na pedagogia freireana todos os saberes são respeitados, a filosofia, a arte, as ciências humanas, sociais e a cultura dos povos ordinários. A educação não deve ser voltada para um modelo empresarial, visando a eficiência, ordem e quantificação do saber, e sim, uma educação que respeite o ser humano na sua incompletude.

Paulo Freire aponta para uma rigorosidade metódica no ato de ensinar, é preciso que o professor não transfira apenas "o conteúdo" curricular, mas instigue a curiosidade epistemológica do sujeito, “(...) ensinar não é transferir conteúdo a ninguém, assim como aprender não é memorizar o perfil do conteúdo do discurso vertical do professor." (FREIRE, 1996, p. 45). Aprender a conhecer, também exige rigor metodológico, está para além do saber escolar, visa conhecer os meios e não apenas o fim, acabado.

A potência dessa proposta antevê objetivos a serem alcançados a fim de proporcionar o direito previsto na Constituição Federal (1988) Capítulo III, artigos 205 e 206, "Visando o pleno desenvolvimento da pessoa". A Seção I sobre Educação propõe caminhos para a garantia desse espaço de formação do sujeito com base em uma rede de ações articuladas pela União, Distrito Federal, Estados e Municípios. Atualmente o Plano Nacional de Educação foi repensado aspirando novas modificações para a qualidade de ensino. Tendo como base as proposições e pontuações realizadas a partir da Conferência Nacional de Educação (Conae) em 2010, a níveis Estadual e Nacional, a proposta do primeiro PNE é revisada. O novo PNE Lei $\mathrm{N}^{\circ} 13.005$ de 2014, objetiva a criação de 20 metas, que de modo geral e sintético prevê a Universalização do ensino para atender crianças e adolescentes dos 4 até os 17 anos na educação básica, a ampliação das matrículas nas redes de ensino público, atingir as marcadas estipuladas pelo Índice de Desenvolvimento da Educação Básica (IDEB), ampliar o ensino superior e a formação de professores, bem como melhorias nas condições de trabalho e a expansão da escola de Tempo Integral.

O ponto central, nessa ótica do novo documento, vem minuciar a discussão propostas para as escolas de tempo integral. Em consonância com as metas de criação de novas escolas, atendimento qualificado e formação de profissionais, a lei prevê a criação de um plano de valorização do magistério e da melhra significativa do olhar do formador. 


\section{Referências}

ALVES, Nilda. A compreensão de políticas nas pesquisas com os cotidianos: para além dos processos de regulação. Educ. Soc., Campinas, v. 31, n. 113, p. 1195-1212, out.-dez. 2010.

AZEVEDO, Fernando. Manifesto dos pioneiros da educação nova. Revista ISTEDBR On-line, Campinas, n. especial, p.188-204, ago. 2006 - ISSN: 1676-2584. Disponível em: http://www.histedbr.fe.unicamp.br/revista/edicoes/22e/doc1 22e.pdf. Acesso em: 09 de fevereiro de 2018 .

BRASIL. Lei de Diretrizes e Bases da Educação Nacional, 9.394/96, de 23 de dezembro. Estabelece as Diretrizes e Bases da Educação Nacional. Diário Oficial [da República Federativa do Brasil], Brasília, DF, 23 dez. 1996. P. 27833. Disponível em:

http://www.planalto.gov.br/ccivil_03/leis/L9394.htm . Acesso em: 29 jul. 2013.

BRASIL. Lei no 13.005, de 25 de junho. Aprova o Plano Nacional de Educação - PNE e dá outras providências, 2014. Diário Oficial [da República Federativa do Brasil], Brasília, DF, 26 de jun. 2015. P. 1. Disponível em: http://www.fnde.gov.br/fnde/legislacao/leis/item/5774- lein\%C2\%BA13-005,-de-25-de-junho-de-2014 . Acesso em: 15 jul. 2015.

BRASIL. Ministério da Educação. Parecer Conselho Nacional de Educação Câmara de Educação Básica n 9/ 2009. Estudo sobre a Lei do Piso Salarial. Brasília, DF, 2009.

Disponível em: http://portal.mec.gov.br/dmdocuments/pceb009_09.pdf. Acesso em: 15 jul. 2015. DELORY-MOMBERGER, Christine. Construção e transmissão da experiência nos processos de aprendizagem e de formação. In: ABRAHÃO, Maria Helena Menna Barreto; FRISON, Lourdes Maria Bragagnolo; BARREIRO, Cristhianny Bento (Org.). A nova aventura (auto)biográfica: tomo I [recurso eletrônico]. Dados eletrônicos. Porto Alegre: EDIPUCRS, 2016.

FREIRE, Paulo. Pedagogia da indignação: cartas pedagógicas e outros escritos. São Paulo: UNESP, 2000.

FREIRE, Paulo. Pedagogia do oprimido. São Paulo: UNESP, 2000.

FREIRE, Paulo. Pedagogia da autonomia: saberes necessários à prática educativa. 25 ed. São Paulo. Paz e Terra, 1996.

GADOTTI, Moacir. Lições de Freire. Rev. Fac. Educ.São Paulo, v. 23, n. 1-2, Jan. 1997.

GADOTTI, Moacir. Pedagogia da Práxis. 5ª ed. São Paulo: Cortez, 2010

JOSSO, Marie-Christine. Experiências de vida e formação. Natal: EDUFRN; São Paulo:

Paulus, 2010. 
LÔBO, Yolanda Lima; TORRES, Aline Camargo; VOGAS, Helen Cristine. Darcy Ribeiro: o brasileiro. Rio de Janeiro: Quartet, 2008.

MORIN, Edgar. Ciência com consciência. $8^{\mathrm{a}}$ ed. Rio de Janeiro: Bertrand Brasil, 2005.

A cabeça bem feita: repensar a reforma, reformar o pensamento. Trad. Eloá Jacobina. $18^{\mathrm{a}}$ ed. Rio de Janeiro: Bertrand Brasil, 2010.

RIBEIRO, Darcy. O Livro dos CIEPS. Rio de Janeiro: Bloch Editores, 1986.

\footnotetext{
${ }^{i}$ Atua como professora Adjunta da Faculdade de Filosofia Ciências e Letras de Macaé FAFIMA e como docente na Rede Municipal de Ensino de Itaboraí - RJ. Doutoranda em Educação - Universidade Federal Fluminense/ Linha de pesquisa: Ciência, Cultura e Educaão (CCE). Mestre em Educação pelo Programa de Pós-graduação em Educação: Processos Formativos e Desigualdades Sociais - PPGEDU da Faculdade de Formação de Professores na Universidade do Estado do Rio de Janeiro (FFP/ UERJ) . Especialista, latto sensu, em Educação Básica/ Gestão Escolar pela Universidade do Estado do Rio de Janeiro (FFP/ UERJ). Graduada em Pedagogia pela Universidade do Estado do Rio de Janeiro (FFP/ UERJ) .

${ }^{i i}$ Atualmente é professora em regime parcial da Faculdade CNEC Ilha do Governador dos cursos de Pedagogia, Engenharia e Administração. Mestre pelo Programa de Pós-graduação em Educação: Processos Formativos e Desigualdades Sociais (FFP/UERJ). Possui graduação em licenciatura plena em Pedagogia pela Universidade do Estado Rio de Janeiro- Faculdade de Formação de Professores- UERJ/ FFP (2011) e em Psicologia (bacharelado) pela Faculdades Integradas Maria Thereza- FAMATH/ RJ (2016). Tem especialização no campo da Arteterapia e Expressões Criativas pela Faculdade das Ciências e da Saúde de São Paulo- FACIS IBEHE/ SP (2013) e em Psicopedagogia Clínica e Institucional pela Faculdades Integradas Maria Thereza- FAMATH/ RJ (2015). Estudante do curso de Filosofia (bacharelado e licenciatura) da Universidade do Estado do Rio de Janeiro- UERJ. Também está em formação em Terapia de Casal e Família ministrada pelo Centro de Atendimento e Aperfeiçoamento em Psicologia- CAAPSY/ RJ.
} 